Augusto Afonso Guerra Júnior ${ }^{1,111}$

Grazielle Dias Silva"

Eli Iola Gurgel Andrade'

Mariângela Leal Cherchiglia'

Juliana de Oliveira Costa"'

Alessandra Maciel Almeida'

Francisco de Assis Acurcio ${ }^{1, \text { III }}$

Departamento de Medicina Preventiva e Social. Faculdade de Medicina. Universidade Federal de Minas Gerais. Belo Horizonte, MG, Brasil

Superintendência de Assistência Farmacêutica. Secretaria de Estado de Saúde de Minas Gerais. Belo Horizonte, MG, Brasil

III Departamento de Farmácia Social. Faculdade de Farmácia. Universidade Federal de Minas Gerais. Belo Horizonte, MG, Brasi

Correspondence:

Augusto Afonso Guerra Júnior

Departamento de Farmácia Social

Faculdade de Farmácia - UFMG

Av. Presidente Antônio Carlos, 6627 Campus

Pampulha

31270-901 Belo Horizonte, MG, Brasil

E-mail: augustoguerramg@gmail.com

Received: 3/6/2014

Approved: 9/11/2014

Article available from: www.scielo.br/rsp

\section{Cyclosporine versus tacrolimus: cost-effectiveness analysis for renal transplantation in Brazil}

\author{
Análise de custo-efetividade: \\ ciclosporina versus tacrolimo para \\ transplante renal no Brasil
}

\begin{abstract}
OBJECTIVE: To analyze the cost-effectiveness of treatment regimens with cyclosporine or tacrolimus, five years after renal transplantation.

METHODS: This cost-effectiveness analysis was based on historical cohort data obtained between 2000 and 2004 and involved 2,022 patients treated with cyclosporine or tacrolimus, matched 1:1 for gender, age, and type and year of transplantation. Graft survival and the direct costs of medical care obtained from the National Health System (SUS) databases were used as outcome results.
\end{abstract}

RESULTS: Most of the patients were women, with a mean age of 36.6 years. The most frequent diagnosis of chronic renal failure was glomerulonephritis/nephritis (27.7\%). In five years, the tacrolimus group had an average life expectancy gain of 3.96 years at an annual cost of $\mathrm{R} \$ 78,360.57$ compared with the cyclosporine group with a gain of 4.05 years and an annual cost of $\mathrm{R} \$ 61,350.44$.

CONCLUSIONS: After matching, the study indicated better survival of patients treated with regimens using tacrolimus. However, regimens containing cyclosporine were more cost-effective.

DESCRIPTORS: Immunosuppressive Agents, therapeutic use. Kidney Transplantation, economics. Graft Survival. Transplantation Tolerance, drug effects. Cost-Benefit Analysis. Unified Health System. Cohort Studies. 


\section{RESUMO}

OBJETIVO: Analisar custo-efetividade de regimes terapêuticos com ciclosporina ou tacrolimo cinco anos após transplante renal.

MÉTODOS: Análise de custo-efetividade com base em dados de coorte histórica 2000-2004, com 2.022 pacientes tratados com ciclosporina ou tacrolimo e pareados 1:1 segundo sexo, idade, tipo e ano de transplante. A sobrevida do enxerto e os custos diretos de cuidados médicos a partir das bases de dados do Sistema Único de Saúde foram utilizados como medida de resultado.

RESULTADOS: A maioria dos pacientes era do sexo feminino e média de idade de 36,6 anos. O diagnóstico mais frequente de insuficiência renal crônica foi a glomerulonefrite/nefrite (27,7\%). Em cinco anos, o grupo tacrolimo obteve uma expectativa de vida média de 3,96 anos de vida ganhos ao custo anual de $\mathrm{R} \$ 78.360,57$ ante 4,05 anos de vida ganhos e de $\mathrm{R} \$ 61.350,44$ para ciclosporina.

CONCLUSÕES: Após o pareamento, o estudo não mostrou melhor sobrevida dos pacientes com regimes que usam tacrolimo. Além disso, regimes contendo ciclosporina foram mais custo-efetivos.

DESCRITORES: Imunossupressores, uso terapêutico. Transplante de Rim, economia. Sobrevivência de Enxerto. Tolerância ao Transplante, efeitos de drogas. Análise Custo-Benefício. Sistema Único de Saúde. Estudos de Coortes.

\section{INTRODUCTION}

Renal disease is mainly caused by diabetes mellitus and arterial hypertension and can be defined as an injury arising from multiple causes, leading to a progressive loss of renal function. ${ }^{5}$ In the disease's final stage, the available renal replacement therapies are hemodialysis, peritoneal dialysis, and renal transplantation. ${ }^{5}$ Kidney transplantation is recognized as the preferred approach for chronic kidney disease treatment, from both clinical and economical perspectives. Technological advances in immunosuppressive therapy have contributed significantly to the consideration of kidney transplantation as the best option for chronic kidney disease. The main goal of such therapy is to prolong graft survival by preventing acute and chronic rejection of the transplanted organ. ${ }^{7}$ Chronic rejection represents $20.0 \%-70.0 \%$ of graft losses after the first year of transplantation, and the risk factors of chronic rejection are failure of the immunosuppressive regimen used and the presence and intensity of acute rejection episodes. ${ }^{\mathrm{a}}$

Clinical immunosuppression began in the early 1950 s with the use of glucocorticoids combined with azathioprine and/or anti-lymphocyte globulins. In the early 1980s, cyclosporine was introduced into the market and represented a significant gain in renal allograft survival. Cyclosporine, which is extracted from the Tolypocladium inflatum cytoplasmic fungus, inactivates calcineurin and prevents interleukin (IL)-2 gene transcription. Cyclosporine may lead to adverse events such as nephrotoxicity, chronic hemolytic uremic syndrome, hyperlipidemia, hypertension, gingival hyperplasia, diabetes mellitus, and tremors. ${ }^{1, \mathrm{~b}}$ Tacrolimus, a polycyclic macrolide, emerged in the early 1990 s as a therapeutic alternative to cyclosporine. Due to its higher affinity for calcineurin, it has been presented to the market as more potent than cyclosporine. Similar to cyclosporine, tacrolimus can cause nephrotoxicity and hemolytic uremic syndrome, but causes fewer episodes of hyperlipidemia, hypertension, and cosmetic effects. ${ }^{1,16}$ Nevertheless, it is associated with a higher incidence of diabetes mellitus after transplantation..$^{22}$ Since 1999, other drugs have been increasingly become available, such as sirolimus, a macrolide with a structure similar to that of tacrolimus, and more recently, everolimus. ${ }^{1}$

a Sociedade Brasileira de Nefrologia. Diretrizes em transplante renal. São Paulo; 2006 [cited 2008 Jun 13 ]. Available from: http://www.sbn.org.br/diretrizes

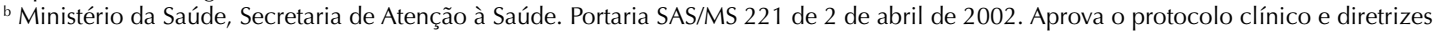
terapêuticas de medicamentos excepcionais e de alto custo no SUS. Diario Oficial Uniao [Internet]. abr 2002 [cited 2008 Jul 29] sessão 1. Pg. 59. Available from: http://dtr2001.saude.gov.br/sas/PORTARIAS/PORT2002/PT-221.htm 
Worldwide, Brazil is the second in the number of transplants performed annually, after only the United States. Most transplantations in Brazil are performed as per the Brazilian Unified Health System (SUS), which in 2013 allowed 4,671 kidney transplants, corresponding to a cost of approximately 100 million dollars. ${ }^{\mathrm{c}}$ Actions to improve the care of patients with renal disease include the publication of the Clinical Protocols and Therapeutic Guidelines ${ }^{\text {b }}$ in 2002 to ensure comprehensive pharmaceutical assistance for the high-cost drugs used in kidney transplantation. Also, in 2004, a National Care Policy for Persons with Renal Disease targeted specific actions in renal replacement therapies. ${ }^{\mathrm{d}}$

The Clinical Protocol and Therapeutic Guidelines for kidney transplantation recommend maintaining immunosuppression regimens after transplantation with cyclosporine and concomitant use of azathioprine and corticosteroids. Alternatively, cyclosporine can be replaced by tacrolimus, and azathioprine can be replaced by mycophenolate mofetil or rapamycin. ${ }^{b}$ Despite the rising economic impact of the distribution of these drugs by SUS, the effects on long-term graft and patient survival remain unknown. Thus, the aim of the present study was to analyze the cost-effectiveness of maintenance immunosuppressive regimens with tacrolimus versus those with cyclosporine over a 5-year follow-up period.

\section{METHODS}

We conducted a cost effectiveness analysis using data from a cohort study conducted from January 2000 to December 2004. The study included patients undergoing kidney transplantation who used immunosuppressive regimens containing tacrolimus or cyclosporine in all SUS transplant centers in Brazil. Patients were identified in the SUS national hospital ambulatory and mortality databases by probabilistic record linkage of administrative data. ${ }^{3}$ The linkage allowed the (re)construction of the trajectory of patients on a large scale, and the matching of records from these databases reached $97.3 \%$ agreement between two clerical reviewers. ${ }^{21}$

We evaluated the time-to-failure of immunosuppressive therapy, i.e., graft loss, as death or the resumption of dialysis for more than three months without concomitant use of immunosuppressive drugs. The last recorded date of immunosuppressive drug dispensation or death was considered the event date. Censoring was characterized as loss of follow-up or study completion.

Entry into the cohort was defined as the transplantation date registered at the SUS hospital database. We considered the immunosuppressive regimens containing tacrolimus or cyclosporine, even when combined with other immunosuppressive drugs registered at the SUS ambulatory database. We included only incident patients who underwent transplantation between January 2000 and December 2003 and were followed-up for at least 12 months.

We excluded patients who survived less than six months post-transplantation and those who switched from cyclosporine to tacrolimus-based regimens, or vice versa. Then we matched 1:1 patients in each group by the following variables: type of transplantation (living or deceased donor), sex (male or female), age in years at the time of transplantation, and year of transplantation $(2000,2001,2002$, or 2003). When more than one patient in either group was a therapeutic candidate for pairing by the four variables, the pair allocation was randomly selected.

We used the Kaplan-Meier method to estimate the cumulative survival probability. A significance level of 5\% was considered, and statistical analysis was conducted with R software version 2.5.0 (R Foundation for Statistical Computing). The economic analysis adopted the public financing perspective and was limited to direct health care costs. To assess individual costs, we identified all procedures, and their costs were based on the SUS hospital and ambulatory databases for each patient considering the month as unit of time. From these data, we calculated the amount spent (in Brazilian Real - BRL) per patient, according to the following categories: hospitalization, dialysis, clinical patient monitoring, and drugs supplied (cyclosporine, tacrolimus, other immunosuppressive agents, and other drugs). Thus, we calculated the total expenditure of each group of patients and the average cost per patient (standard deviation) for the period.

Further details of the methodological procedures are described in our previous publication. ${ }^{9}$ We updated the values until December 2012 based on the Consumer Price Index (Índice de Preços ao Consumidor Amplo). ${ }^{\mathrm{e}}$

We developed a Markov model using the TreeAge Pro $^{\circledR} 2009$ program, with the primary focus on a 5-year cost effectiveness analysis to compare the use of tacrolimus versus cyclosporine regimens in preventing graft

\footnotetext{
c Ministério da Saúde, Secretaria de Gestão Estratégica e Participativa, Departamento de Informática do SUS - DATASUS. Brasília (DF); 2014 [cited 2014 Oct 3]. Sistema de Internações Hospitalares do SUS. Available from: http://www2.datasus.gov.br/DATASUS/index.

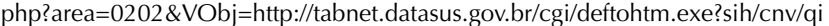

${ }^{d}$ Associação Brasileira de Transplante de Órgãos - ABTO. Dimensionamento dos transplantes no Brasil e em cada estado (2006-2013). Regist Bras Transplantes [Internet]. 2013 [cited 2014 Jul 27];19(4):3-79. Available from: http://www.abto.org.br/abtov03/Upload/file/RBT/2013/ rbt2013-parcial\%281\%29.pdf

e Instituto Brasileiro de Geografia e Estatística. Índice de Preços ao consumidor. Rio de Janeiro; 2012 [cited 2014 Nov 24]. Available from: http://www.ibge.gov.br/home/estatistica/indicadores/precos/inpc_ipca/ipca-inpc_201204_1.shtm
} 
rejection in kidney transplantation. Cyclosporine was selected as the comparative treatment in the model because it is the first choice immunosuppressant in SUS clinical protocols. ${ }^{\mathrm{b}}$

Survival by follow-up year and costs were calculated directly from the historical cohort. The model consisted of two health states: alive with transplant (initial health state) and treatment failure (graft loss and/or death). A discount rate of $5.0 \%$ per year was adopted for the costs and results.

The Markov model was used to estimate clinical benefits in life-years gained (LYG) with a functioning graft and the costs of alternative drugs in the follow-up period. We compared the treatment alternatives according to the incremental cost effectiveness ratio according to the cost effectiveness threshold suggested by the World Health Organization: ${ }^{f} 1-3 \times$ the gross domestic product per capita $(21,252.00 \mathrm{BRL}$ to $63,756.00 \mathrm{BRL}$; reference year, 2011) per life-year adjusted for disability prevented. Because life-years adjusted for disability were estimated, the LYG was considered proxy.

Sensitivity analysis was performed to determine the impact on the estimated incremental cost effectiveness ratio. Unidirectional analysis was conducted by varying the individual values: discount rates $(0.0 \%, 5.0 \%$, and $10.0 \%$ ), costs, magnitude of treatment effectiveness, and graft survival (minimum and maximum values of the transition probabilities).

This study is part of the Pharmacoeconomics and Pharmacoepidemiological Evaluation of High-Cost Drugs in Brazil project (Avaliação farmacoeconômica e epidemiológica do Programa de Medicamentos Excepcionais do SUS no Brasil, 2000-2005), which was approved by the Ethics Committee of Universidade Federal de Minas Gerais (397/2004 and 0101/2006).

\section{RESULTS}

Among 9,298 kidney transplantations, we identified 8,981 different patients. Only $11.0 \%$ of them were not registered as drug users in the ambulatorial SUS system. From January 2000 to December 2004, among the various combinations of drugs supplied by SUS, we observed that 4,392 (49.0\%) patients were exclusively on immunosuppressive regimens based on cyclosporine and 1,294 (14.0\%) patients were exclusively on tacrolimus regimens. Then, we established 1,011 pairs matched by type of transplantation, gender, age, and year of transplantation between the cyclosporine and tacrolimus groups.
Table 1 shows the final distribution of the kidney transplantation patients and their immunosuppressive regimens. Of the 2,022 individuals included in the cohort, the majority $(50.4 \%)$ were female, and the mean age at transplantation was 36.6 years. The most frequent primary causes of chronic kidney disease were glomerulonephritis, interstitial nephritis, pyelonephritis (27.7\%), hypertension, cardiovascular disease (20.4\%), organ and tissue transplantation failure or rejection $(6.3 \%)$, diabetes $(3.6 \%)$, cystic kidney disease $(2.0 \%)$, and other causes and undetermined diagnoses (38.0\%). The large number of patients with undetermined diagnoses may be related to the advanced clinical stage of renal disease in many patients, which complicates the establishment of the disease's etiology. Transplantation was performed with living donors most often (62.7\%). Immunosuppressive treatment failure occurred in $9.7 \%$ of the patients (death in $5.9 \%$ and graft loss in $3.8 \%$ ). Table 2 presents the annual probabilities of graft survival in the period of 1-5 years observed for each group.

Regarding economic assessment, we observed significantly higher spending in the tacrolimus-based regimen group for the following categories of resources: study drug [10.1 million for cyclosporine and 26.9 million for tacrolimus (BRL)], hospitalization [38.5 million for cyclosporine and 40.2 million for tacrolimus (BRL)] (Table 3).

In five years, tacrolimus treatment resulted in an average life expectancy of 3.96 LYG compared with 4.05 LYG in case of cyclosporine, considering a 5.0\% discount on the costs and effects. The annual cost of treatment was BRL 78,360.57 with tacrolimus and BRL $61,350.44$ with cyclosporine. Based on these results, we observed that tacrolimus treatment was more costly and less effective (Table 4).

For the sensitivity analysis, different discount rates $(0.0 \%, 10.0 \%$, and $5.0 \%)$ and the minimum and maximum prices of the medication alternatives also were applied to determine the extension at which the arbitrary selection of the rate affected the study conclusions. In five years, tacrolimus treatment resulted in an expected median graft survival of 4.31 LYG compared with 4.42 LYG obtained with cyclosporine. The annual cost of treatment was BRL $80,061.50$ with tacrolimus and BRL $62,453.42$ with cyclosporine. Applying a $10.0 \%$ discount to the costs and effects, we obtained an average of 3.66 LYG with tacrolimus and 3.74 LYG with cyclosporine. The annual cost of treatment was then BRL 76,914.22 with tacrolimus and BRL 60,410.53 with cyclosporine. In both scenarios, cyclosporine treatment was associated with less cost and greater effectiveness compared with tacrolimus treatment.

${ }^{\mathrm{f}}$ World Health Organization. Cost effectiveness and strategic planning (WHO-CHOICE): cost-effectiveness thresholds. Geneva; 2005 [cited 2014 Nov 24]. Available from: http://www.who.int/choice/costs/CER_thresholds/en 
Table 1. Distribution of kidney transplantation patients receiving immunosuppressive regimens containing cyclosporine or tacrolimus in a matched cohort. Brazil, 2000-2004.

\begin{tabular}{|c|c|c|c|c|c|}
\hline \multicolumn{3}{|c|}{ Cyclosporine } & \multicolumn{3}{|c|}{ Tacrolimus } \\
\hline Regimen & Combination & $\mathrm{n}$ & Regimen & Combination & $\mathrm{n}$ \\
\hline $\begin{array}{l}\text { Cyclosporine } \\
\text { (monotherapy) }\end{array}$ & & 316 & $\begin{array}{c}\text { Tacrolimus } \\
\text { (monotherapy) }\end{array}$ & & 146 \\
\hline $\begin{array}{l}\text { Cyclosporine + } \\
\text { Azathioprine }\end{array}$ & & 229 & $\begin{array}{l}\text { Tacrolimus + } \\
\text { Azathioprine }\end{array}$ & & 231 \\
\hline & + Mycophenolate & 69 & & + Mycophenolate & 53 \\
\hline & $\begin{array}{c}\text { Mycophenolate/ } \\
\text { Sirolimus }\end{array}$ & 9 & & $\begin{array}{c}\text { +Mycophenolate/ } \\
\text { Sirolimus }\end{array}$ & 3 \\
\hline & + Sirolimus & 4 & & + Sirolimus & 1 \\
\hline $\begin{array}{l}\text { Cyclosporine + } \\
\text { Mycophenolate }\end{array}$ & & 335 & $\begin{array}{c}\text { Tacrolimus + } \\
\text { Mycophenolate }\end{array}$ & & 478 \\
\hline & + Sirolimus & 31 & & +Sirolimus & 35 \\
\hline & + Azathioprine & 5 & & + Azathioprine & 36 \\
\hline Cyclosporine + Sirolimus & & 13 & Tacrolimus + Sirolimus & & 28 \\
\hline Total & & 1,011 & Total & & 1,011 \\
\hline
\end{tabular}

Table 2. Annual probability of graft survival (95\% confidence interval) of kidney transplantation patients, according to the therapeutic regimen in a matched cohort. Brazil, 2000-2004.

\begin{tabular}{lcccc}
\hline & \multicolumn{2}{c}{ Cyclosporine } & \multicolumn{2}{c}{ Tacrolimus } \\
\hline Follow-up & Graft survival probability & $95 \% \mathrm{Cl}$ & Graft survival probability & $95 \% \mathrm{Cl}$ \\
\hline $1^{\text {st }}$ year & 0.975 & $0.970 ; 0.988$ & 0.967 & $0.963 ; 0.983$ \\
$2^{\text {nd }}$ year & 0.935 & $0.922 ; 0.954$ & 0.924 & $0.909 ; 0.944$ \\
$3^{\text {rd }}$ year & 0.892 & $0.872 ; 0.919$ & 0.870 & $0.851 ; 0.901$ \\
$4^{\text {th }}$ year & 0.850 & $0.838 ; 0.898$ & 0.870 & $0.783 ; 0.860$ \\
$5^{\text {th }}$ year & 0.820 & $0.762 ; 0.882$ & 0.790 & $0.741 ; 0.849$ \\
\hline
\end{tabular}

We also applied a 5.0\% discount rate to costs and effects and varied the magnitude of treatment effectiveness in the case of graft survival (transition probability minimum and maximum values) to determine the impact on the incremental cost effectiveness ratio estimate. For the maximum values, tacrolimus resulted in an expected median survival of 4.09 LYG, which was less than 4.20 LYG achieved with cyclosporine. The annual cost of treatment was BRL 78,982.95 with tacrolimus and BRL 61,718.68 with cyclosporine. Thus, tacrolimus treatment was more costly and less effective than cyclosporine treatment. For the minimum values, tacrolimus resulted in an expected median survival of 3.83 LYG and cyclosporine resulted in that of 3.95 LYG. The annual cost of treatment was BRL 77,870.27 with tacrolimus and BRL 61,053.77 for cyclosporine. Again, tacrolimus treatment was more costly and less effective than cyclosporine treatment.

\section{DISCUSSION}

In this study with matched groups, no evidence was found of a therapeutic advantage of tacrolimus over cyclosporine in kidney transplantation. Our findings were consistent with a previous review comparing the effects of these two drugs as primary therapy for kidney transplantation that showed significantly reduced graft failure and death in recipients treated with tacrolimus versus those treated with cyclosporine at six months and at three years after transplantation. However, in this review, a significant difference was not observed at one, two, four and five years after transplantation. ${ }^{25}$

A recent retrospective analysis of 51,303 patients reported that after five years, graft survival in recipients of kidney transplants from cadaveric donors was equivalent in patients receiving immunosuppressive regimens based on cyclosporine or tacrolimus. The same study discussed the selection of tacrolimus, because it is most commonly prescribed for patients who are generally considered at high risk for graft failure. The analysis performed across four well-defined risk groups of patients showed no significant differences in survival between those treated with tacrolimus and those treated with cyclosporine in presensitized recipients, 


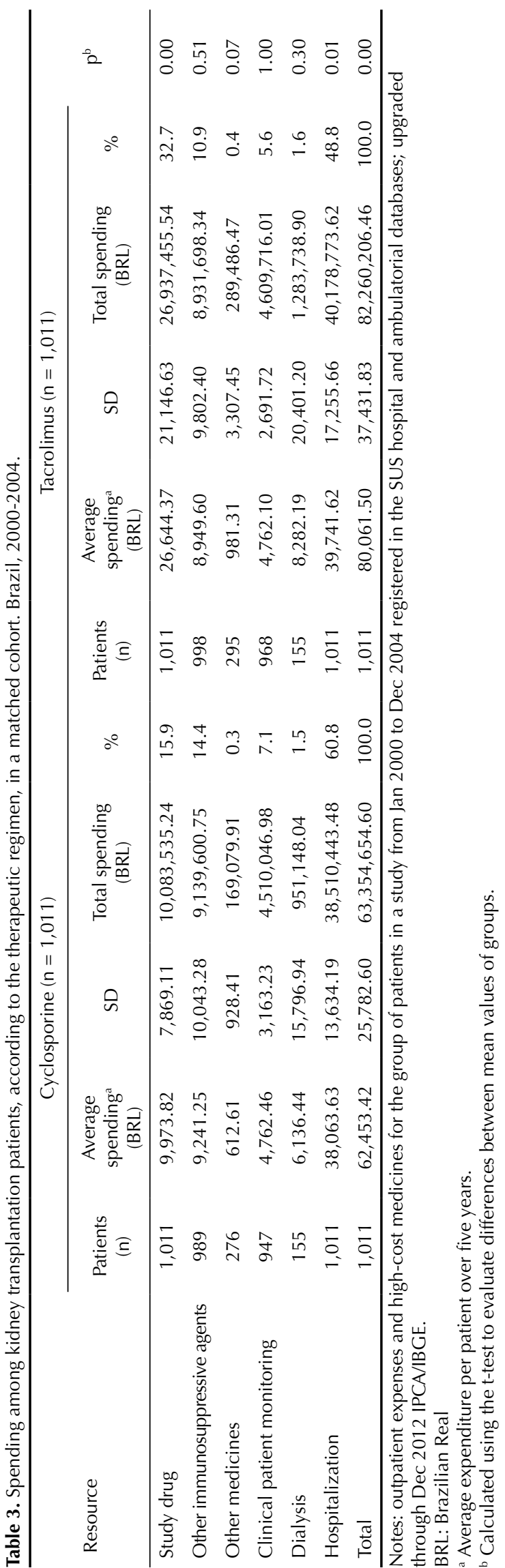

retransplanted patients, diabetes patients, and recipients of grafts from donors aged 65 years or older. ${ }^{17}$

In addition to being considered more appropriate for liver transplantation than kidney transplantation, tacrolimus is associated with the side effect of diabetes development. ${ }^{13,15,17,25}$ Tacrolimus and micophenolate maintenance therapy is also one of the most important risk factors for polyoma virus nephropathy development, which is a common cause of kidney transplant failure. ${ }^{20}$ In Brazil, the most common maintenance regimen used includes cyclosporine, but an increasing number of patients have been treated with tacrolimus. This should not happen, according to clinical protocols in force in Brazil, because most kidney transplantations are performed from living donors, and nearly $80.0 \%$ are performed with organs donated by close relatives. In this situation, a better match between the donor and recipient is expected, and the general recommendation is to use tacrolimus when clinical conditions indicate a higher risk of graft rejection or toxicity to the patient.

In a cohort study of 5,686 patients, with unpaired groups, the treatment failure risk in patients receiving tacrolimus was considered to be 1.38 times higher than in those receiving cyclosporine, after adjusting the model for confounding factors. ${ }^{10} \mathrm{~A}$ lower survival with tacrolimus was also identified in a study of data from the United Network for Organ Sharing in the United States, which included more than 7,000 transplantation patients, and the risk related to tacrolimus was found to be increased by 1.28 -fold. ${ }^{12}$

The widespread use of tacrolimus is usually based on the notion that the drug reduces acute rejection better in comparison with cyclosporine, which would generate graft survival benefits. However, studies with a large number of patients which were controlled for many confounders could not demonstrate differences in graft survival at five years between patients who received tacrolimus and those who received cyclosporine regimens. ${ }^{12,17,25}$ Likewise, the data did not show an advantage in graft survival in the long term with tacrolimus. It should be noted that the five-year follow-up period for the cohort was sufficient to observe the event, even though the length of graft and patient survival reported in the literature was approximately 10 years. An economic evaluation focusing on immunosuppressive regimens used in kidney transplantation in Germany found a small difference in graft survival favoring tacrolimus in a period of 10 years, but due to its considerably higher cost, it was not considered a cost effective alternative. ${ }^{11}$

The assessment of incremental cost effectiveness for the five-year period showed economic dominance of regimens based on cyclosporine over those based on tacrolimus. We highlight the occurrence of major hospitalization expenses and medications for the tacrolimus group during the period. Higher spending on medicines 
Table 4. Results of cost-effectiveness (5.0\% discount on the costs and effects) of treatment regimens with cyclosporine or tacrolimus after kidney transplantation. Brazil, 2000-2004.

\begin{tabular}{lcccccc}
\hline Regimen & Cost (BRL) & $\begin{array}{c}\text { Incremental cost } \\
(\mathrm{BRL})\end{array}$ & $\begin{array}{c}\text { Effectiveness } \\
(\mathrm{LYG})\end{array}$ & $\begin{array}{c}\text { Incremental } \\
\text { effectiveness }\end{array}$ & $\begin{array}{c}\text { CER } \\
(\mathrm{BRL} / \mathrm{LYG})\end{array}$ & ICER \\
\hline Cyclosporine & $61,350.44$ & & 4.05 & & $15,146.56$ & \\
Tacrolimus & $78,360.57$ & $17,010.13$ & 3.96 & -0.09 & $19,791.59$ & Dominated \\
\hline
\end{tabular}

LYG: life-years gained; CER: Cost effectiveness ratio; ICER: Incremental cost effectiveness ratio; BRL: Brazilian Real

was already expected, as once monthly tacrolimus treatment was 2.6 times more expensive than that with cyclosporine, but it was hoped that other expenses, primarily related to hospitalization, would be lower, which could afford a positive incremental value with regimens based on tacrolimus.

The variables identified as risk factors for clinical and surgical kidney transplantation were as follows: age less than five years or greater than 50 years and systemic diseases [diabetes mellitus, amyloidosis, Fabry disease, scleroderma, previous gastrointestinal disease (peptic ulcer, pancreatitis, liver disease, diverticulosis, morbid obesity, and malnutrition), previous malignancy, previous transplantations, and others]. ${ }^{1}$ In a previous publication focusing on this cohort, both age and the presence of diabetes were associated with a high risk of treatment failure, which impacted patient survival. ${ }^{10}$ Hypertension and heart disease did not appear as risk factors in the final model. One explanation is that these conditions are associated more with the baseline diagnosis, and these patients are better able to control their disease after transplantation, considering the focus that SUS has given to them. However, this interpretation requires confirmation in more specific studies.

The literature indicates that diabetes, hypertension, and glomerulonephritis, in descending order, are the main primary diagnoses that lead to chronic kidney disease among patients undergoing dialysis. ${ }^{4}$ The present study identified these diagnoses, but in a different order. One hypothesis for this difference is that nephritis does not represent a chronic condition, and thus, these patients would be more likely to be eligible for kidney transplantation than those with hypertension and diabetes. Another aspect to be considered is the high prevalence of other undetermined causes and diagnoses observed in this administrative database. A review showed that the influence of sociocultural and socioeconomic disparities on kidney transplantation outcomes remains largely unclear and identified a need for more research to better understand the factors that contribute to these disparities and their mechanisms. ${ }^{8}$

In addition, a variety of factors influence graft survival in the short and long term, including the following: the combination of antigens between the donor and recipient with respect to histocompatibility, ABO blood group, a higher level of panel reactive antibodies, race, gender, ages of donor and recipient, ischemic time for donor organ, organ size compatibility, acute rejection crises, postoperative acute tubular necrosis, time of dialysis, and history of previous transplantations. Besides these, induction therapy with a lymphocyte depletion agent or an interleukin-2 receptor antagonist can effectively protect against rejection in the first crucial months after transplantation. However, there is no evidence of its benefits on graft survival in the long-term. ${ }^{1,2,7,16,22, \mathrm{~b}}$ Information on most of these factors was not available for this study. However, we considered the evidence of an increased risk of rejection associated with sex, recipient age, and type of transplantation, to pair the patient groups. ${ }^{14}$ Also, in the SUS, kidney transplantations are performed with living and cadaveric donors. ${ }^{\mathrm{b}}$

Despite the increased availability of immunosuppressive drugs, the greatest benefit of such treatment seems to be reducing the number of episodes of acute rejection, which is one of the main risk factors for chronic allograft nephropathy. ${ }^{19}$ However, the effects on shortand long-term survival have been less substantiated despite the addition of new medicines, such as tacrolimus, to the initial therapeutic regimen involving azathioprine and prednisone. Studies showed an initial increase in survival among transplantation patients who received a therapeutic regimen based on tacrolimus, compared with those who received cyclosporine-based regimens. Nevertheless, long-term studies did not uniformly confirm this apparent advantage of tacrolimus immunosuppression. ${ }^{12,14,19}$

Observational data are particularly likely to be affected by confounding factors in studies focusing on therapeutic effects, because the reasons why a physician or patient selects a particular treatment are also strongly linked to the health outcome. ${ }^{6}$ Another limitation of this study is related to the data collection method. We used data recorded in large administrative databases developed by the health system, which were collected retrospectively; these data may not be complete or may be of low quality. ${ }^{23}$ Moreover, information on a variety of factors that influence graft survival, such as ischemia time, histocompatibility, and time to dialysis, in the short and long term were not available in the database.

Regarding the use of health expenditures as a proxy for costs, in other studies, the cost and production functions are defined as expenditures executed by the financier 
or consumer. ${ }^{18}$ The amount paid by the Ministry of Health in ambulatorial and hospital systems usually reflects the actual market value of the procured drugs and procedures performed by the various hospital and outpatient centers. However, this potential difference occurs equally among the evaluated groups, because the rule of finance is the same for both.

Despite these limitations, the historical cohort has proven to be useful for the study of exposure effects and economic analysis. Effectiveness and health care outcome evaluations like this study are being performed increasingly more often, because of the expansion of disease registration and large administrative databases. ${ }^{6}$ These types of studies contribute to the current debate about the importance of observational studies as a complementary source of scientific evidence for physicians, health planners, regulators, managers, and legislators. ${ }^{24}$

\section{REFERENCES}

1. Abbud Filho M, Ramalho HJ. Revisão/atualização em transplante renal: novos agentes imunossupressores. J Bras Nefrol. 1997; 19(2):215-23.

2. Bunnapradist S, Daswani A, Takemoto S K. Graft survival following living-donor renal transplantation: a comparison of tacrolimus and cyclosporine microemulsion with mycophenolate mofetil and steroids. Transplantation. 2003;76(1):10-5. DOI:10.1097/01.TP.0000079965.62765.1A

3. Cherchiglia ML, Guerra Júnior AA, Andrade EIG, Machado CJ, Acúrcio FA, Meira Júnior W, et al. A construção da base de dados nacional em Terapia Renal Substitutiva (TRS) centrada no indivíduo: aplicação do método de linkage determinístico probabilístico. Rev Bras Estud Popul. 2007;24(1):163-7. DOI:10.1590/S0102-30982007000100010

4. Cherchiglia ML, Machado EL, Szuster DAC, Andrade EIG, Acúrcio FA, Caiaffa WT, et al. Perfil epidemiológico dos pacientes em terapia renal substitutiva no Brasil, 20002004. Rev Saude Publica. 2010;44(4):639-49. DOI:10.1590/S0034-89102010000400007

5. Fauci AS, Braunwald E, Kasper DL, Hauser SL, Longo DLA, Jameson JL, et al, editores. Harrison medicina interna. 17.ed. Rio de Janeiro: McGraw-Hill; 2008-2009.

6. Gail MH, Benichou J, editors. Encyclopedia of epidemiologic methods. Chichester: J.Wiley \& Sons; 2000. Occupational Epidemiology. p.669

7. Gentil MA, Cantarell Aixendri C, GonzálezRoncero FM, Franco MJE, López de Mendonza Martinez M. Impact of the new drugs in the cost of maintenance immunosuppression of renal transplantation. Is it justified? Nephrol Dial Transplant. 2004;19(Suppl 3):iii77-82. DOI:10.1093/ndt/gfh1021

8. Gordon EJ, Ladner DP, Caicedo JC, Franklin J. Disparities in kidney transplant outcomes:
Because the treatment regimen choice is not random, we sought to minimize the pairing differences between groups. However, it was beyond the scope of the research to examine the reasons why doctors recommended a specific immunosuppressive regimen. The findings of this study should not be generalized to other situations. However, they reflect final health outcomes related to the use of immunosuppressive regimens prescribed to more than 2,000 patients who underwent kidney transplant in Brazil.

In conclusion, tacrolimus treatment did not show higher effectiveness than cyclosporine treatment. Therefore, the main component that affected the cost effectiveness ratio was the price of the immunosuppressants. The economic results presented herein may be useful for price regulation, both with regard to new drug price policies and to annual increases granted to the manufacturer.

a review. Semin Nephrol. 2010;30(1):81-9.

DOI:10.1016/j.semnephrol.2009.10.009

9. Guerra Jr AA, Cesar CC, Cherchiglia ML, Andrade El, Queiroz OV, Silva GD, et al. Cyclosporine versus tacrolimus in immunosuppressive maintenance regimens in renal transplants in Brazil: survival analysis from 2000 to 2004. Ann Pharmacother. 2010;44(1):192-201. DOI:10.1345/aph.1M244

10. Guerra Junior AA, Acúrcio FA, Andrade EIG, Cherchiglia ML, Cesar CC, Queiroz OV, et al. Ciclosporina versus tacrolimus no transplante renal no Brasil: uma comparação de custos. Cad Saude Publica. 2010;26(1):163-74. DOI:10.1590/S0102-311X2010000100017

11. Jürgensen JS, Arns W, Haß B. Cost-effectiveness of immunosuppressive regimens in renal transplant recipients in Germany: a model approach. Eur J Health Econ. 2010;11(1):15-25. DOl:10.1007/s10198-009-0148-3

12. Kaplan B, Schold JS, Meier-Kriesche HU. Long-term graft survival with neoral and tacrolimus: a paired kidney analysis. J Am Soc Nephrol. 2003;14(11):2980-4. DOI:10.1097/01.ASN.0000095250.92361.D5

13. Kramer BK, Montagnino G, Del Castillo D, Margreiter $\mathrm{R}$, Sperschneider H, Olbricht CJ, et al. Efficacy and safety of tacrolimus compared with cyclosporin A microemulsion in renal transplantation: 2 year followup results. Nephrol Dial Transplant. 2005;20(5):968-73. DOI:10.1093/ndt/gfh739

14. Leichtman AB. Balancing efficacy and toxicity in kidney-transplant immunosuppression. N Engl J Med. 2007;357(25):2625-7. DOI:10.1056/NEJMe078181

15. Margreiter R; European Tacrolimus vs Ciclosporin Renal Transplantation Study Group. Efficacy and safety of tacrolimus compared with ciclosporin microemulsion in renal transplantation: a randomised multicentre study. Lancet. 2002;359(9308):741-6. DOI:10.1016/S0140-6736(02)07875-3 
16. Martin Garcia D, Martin Gago J, Mendiluce A, Gordillo R, Bustamente J. Tacrolimus-Basiliximab versus Cyclosporine-Basiliximab in renal transplantation "de novo": acute rejection and complications. Transplant Proc. 2003;35(5):1694-6. DOI:10.1016/S0041-1345(03)00576-1

17. Opelz G, Dohler B. Influence of immunosuppressive regimens on graft survival and secondary outcomes after kidney transplantation. Transplantation. 2009;87(6):795-802. DOI:10.1097/TP.0b013e318199c1c7

18. Orme ME, Jurewicz WA, Kumar N, McKechnie TC. The cost effectiveness of tacrolimus versus microemulsified cyclosporine: a 10-year model of renal transplantation outcomes. Pharmacoeconomics. 2003;21(17):1263-76. DOI:10.2165/00019053-200321170-00003

19. Pirsch JD, Miller J, Deierhoi MH, Vincenti F, Filo RS. A comparison of tacrolimus (FK506) and cyclosporine for immunosuppression after cadaveric renal transplantation. Transplantation. 1997;63(7):977-83.

20. Prince O, Savic S, Dickenmann M, Steiger J, Bubendorf L, Mihatsch MJ. Risk factors for polyoma virus nephropathy. Nephrol Dial Transplant. 2009;24(3):1024-33. DOI:10.1093/ndt/gfn671

21. Queiroz OV, Guerra Júnior AA, Machado CJ, Andrade LG, Meira Júnior W, Acúrcio AS, et al. Building the
National Database on Renal Replacement Therapy focused on the individual: probabilistic record linkage of death registries at the high complexity procedures authorization subsystem (Apac/SIA/SUS) and at the Mortality Information System (SIM) - Brazil, 2000-2004. Epidemiol Serv Saude, 2009;18(2):107-20.

22. Radermacher J, Meiners $M$, Bramlage $C$, Kliem V, Behrend M, Schlitt HJ, et al. Pronounced renal vasoconstriction and systemic hypertension in renal transplant patients treated with cyclosporine A versus FK 506. Transp/ Int. 1998;11(1):3-10.

23. Rothman KJ, Greenland S. Cohort studies. In: Rothman KJ, Greenland S, Lash TL. Modern epidemiology. 3.ed. Philadelphia: Lippincott Williams \& Wilkins; 2008. Section 3.7; p.109.

24. Takemoto SK, Arns W, Bunnapradist S, Garrison LP, Guirado L, Kalo Z, et al. Expanding the evidence base in transplantation: the complementary roles of randomized controlled trials and outcomes research. Transplantation. 2008;86(1):18-25. DOI:10.1097/TP.0b013e31817d4df5

25. Webster AC, Woodroffe RC, Taylor RS, Chapman JR, Craig JC. Tacrolimus versus cyclosporine as primary immunosuppression for kidney transplant recipients: meta-analysis and meta-regression of randomized trial data. BMJ. 2005;331(7520):810-21. DOI:10.1136/bmj.38569.471007.AE

Research supported by the Ministério da Saúde (4863/2005), the Conselho Nacional de Desenvolvimento Científico e Tecnológico (CNPq - Process 402691/2005-9) and the Fundação de Amparo e Pesquisa do Estado de Minas Gerais (FAPEMIG - CDS APQ-4611-5.01/07).

Based on the doctoral thesis of Guerra Jr AA, titled: "Avaliação de custo-efetividade entre esquemas imunossupressores utilizados no transplante renal: um estudo farmacoepidemiológico e farmacoeconômico sobre o programa nacional de medicamentos excepcionais no SUS de 2000 a 2004," and presented to the Postgraduation Program in Public Health of the Universidade Federal de Minas Gerais, in 2010.

The authors declare no conflict of interest.

\section{ERRATUM}

No artigo: "Cyclosporine versus tacrolimus: cost-effectiveness analysis for renal transplantation in Brazil" publicado no periodico "Revista de Saúde Pública”, volume 49 de 2015, em Conclusions of the Abstract.

Where it reads:

"After matching, the study indicated better survival of patients treated with regimens using tacrolimus. However, regimens containing cyclosporine were more cost-effective."

It should read:

"After matching, the study did not indicate better survival of patients treated with regimens using tacrolimus. Moreover, regimens containing cyclosporine were more cost-effective." 